\title{
Numerical simulations of oceanic oxygen cycling in the FAMOUS Earth-System model: FAMOUS-ES, version 1.0
}

\author{
J. H. T. Williams ${ }^{1}$, I. J. Totterdell ${ }^{2}$, P. R. Halloran ${ }^{3, *}$, and P. J. Valdes ${ }^{1}$ \\ ${ }^{1}$ BRIDGE, School of Geographical Sciences, University of Bristol, Bristol, BS8 1SS, UK \\ ${ }^{2}$ Met Office Hadley Centre, FitzRoy Road, Exeter, EX1 3PB, UK \\ ${ }^{3}$ School of Geography, University of Exeter, Exeter, EX4 4RJ, UK \\ * previously at: Met Office Hadley Centre, FitzRoy Road, Exeter, EX1 3PB, UK
}

Correspondence to: J. H. T. Williams (jonny.williams@bristol.ac.uk)

Received: 9 January 2014 - Published in Geosci. Model Dev. Discuss.: 21 February 2014

Revised: 3 June 2014 - Accepted: 4 June 2014 - Published: 15 July 2014

\begin{abstract}
Addition and validation of an oxygen cycle to the ocean component of the FAMOUS climate model are described. At the surface, FAMOUS overestimates northern hemisphere oxygen concentrations whereas, at depth, the southern hemisphere values are too low. Surface validation is carried out with respect to HadGEM2-ES where, although good agreement is generally found, discrepancies are mainly attributed to disagreement in surface temperature structure between the models. The disagreement between the models at depth in the Southern Hemisphere is attributed to a combination of excessive surface productivity in FAMOUS' equatorial waters (and its concomitant effect on remineralisation at depth) and its reduced overturning circulation compared to HadGEM2-ES. For the Atlantic basin FAMOUS has a circulation strength of $12.7 \pm 0.4 \mathrm{~Sv}$ compared to $15.0 \pm 0.9$ for HadGEM2-ES. Global- and basin-scale decomposition of meridional overturning circulation, oxygen concentration and apparent oxygen utilisation (AOU) - a measure of the departure from equilibrium with the atmosphere - allows specific features of the climatology to be assigned to particular basins. For example, the global signal in overestimation of low-latitude Northern Hemisphere oxygen at intermediate depths is attributed to the Pacific. In addition, the inclusion of the AOU analysis enables explanation of oxygen-deficient deep water in the Southern Hemisphere which is not seen in the Northern Hemisphere.
\end{abstract}

\section{Introduction}

The ongoing model development of the FAMOUS climate model (Jones et al., 2005; Smith et al., 2008; Smith, 2012; Williams et al., 2013) in contrast to its higher resolution parent model HadCM3 (Gordon et al., 2000; Pope et al., 2000) is a testament to its utility as a fast (Fast Met Office UK Universities Simulator; FAMOUS) model which is capable of running at least 10 times faster than HadCM3. Model development with the latest Met Office Hadley Centre models continues apace however. Indeed huge improvements in model physics too numerous to detail here have been achieved via HadCM4 (Webb et al., 2001), HadGEM1 (e.g. Martin et al., 2006), HadGEM2 (e.g. Collins et al., 2011) and HadGEM3 (Hewitt et al., 2011), arguably the most notable of which are the introduction of a new semi-Lagrangian dynamical core in HadGEM1, and new ocean and cloud schemes in HadGEM3. It is not just the physical model components which have undergone model development however. HadCM3LC was the first coupled climate model to include a fully interactive carbon cycle (Cox et al., 2000). HadGEM2-ES has extended the Earth System complexity represented within HadCM3LC by evolving the ocean carbon cycle sub-model, as well as the addition of a non-sulfate aerosols, aerosol indirect effects, interactive dust emission, and interactive tropospheric chemistry (Collins et al., 2011; Bellouin et al., 2011).

The configuration of the FAMOUS model presented here includes both terrestrial and oceanic carbon cycles - however, the atmospheric carbon dioxide concentration is fixed. The precise configuration is described in detail in the next section. 
The continued use of the HadCM3 family of models is justified since it has been shown to continue to perform well compared to more recent models. For example, Reichler and Kim (2008) show that HadCM3 performs statistically better than many other models in the Intergovernmental Panel on Climate Change's "CMIP3" archive despite having been documented several years earlier. In addition to this, FAMOUS is capable of running for sufficiently long to allow more slowly evolving components of the Earth system to be investigated.

There are many potential applications of the new model functionality presented here, for example Cretaceous oceanic anoxic events, OAEs (e.g. Monteiro et al., 2012). These were episodes in which potentially the entire global ocean was significantly depleted in oxygen, clearly with huge ramifications for global biogeochemical cycles. This paper however will focus solely on the model development undertaken to include cycling of oxygen in the FAMOUS model.

Previous oxygen modelling studies include those of Matear et al. (2000) (with particular focus on future changes to the Southern Ocean), Bopp et al. (2002) (trends in oceanatmosphere oxygen fluxes, including partitioning into ocean surface warming and changes in stratification) and Frölicher et al. (2009) (small ensemble of climate simulations studying both human- and volcanically induced perturbations to the ocean's oxygen cycle). An excellent review of oxygen modelling with particular reference to hypoxic (reduced oxygen) waters can be found in Peña et al. (2010) and a detailed discussion of $\mathrm{P} / \mathrm{N} / \mathrm{C}_{\text {org }} / \mathrm{O}_{2}$ (Redfield) ratios in seawater can be found in Anderson and Sarmiento (1994).

\section{Theory and model description}

This work describes the inclusion of oxygen cycling into FAMOUS' ocean GCM (General Circulation Model) code. The method followed is that of the second phase of the Ocean Carbon-Cycle Model Intercomparison Project, OCMIP2, as specifically implemented into the HadGEM2-ES code. The formalism used is that of Garcia and Gordon (1992) via the protocols of the Ocean Carbon-Cycle Model Intercomparison Project (Najjar and Orr, 1999). Full details of the biogeochemical cycling system present in FAMOUS (without oxygen) can be found in Palmer and Totterdell (2001). In the present work, the rate of biological production of oxygen is simply proportional to the rate of consumption of DIC (dissolved inorganic carbon),

$\frac{\mathrm{dO}}{\mathrm{d} t}=-\alpha \frac{\mathrm{dC}}{\mathrm{d} t}$,

where $\mathrm{O}$ and $\mathrm{C}$ are the concentrations of oxygen and carbon (represented by dissolved inorganic carbon, DIC, in the model) and $\alpha$ is the constant of proportionality (equal to $\frac{138}{106}$ ). More information on the precise origin of this coefficient's value can be found in Anderson and Sarmiento (1994). Although the continuity equations of oxygen and carbon dioxide are trivially similar, the form of the air-sea flux equations is quite different for oxygen. The form of the flux is as follows:

$F_{\mathrm{O}}=\rho k(1-A)\left(\mathrm{O}_{\mathrm{sat}}-\mathrm{O}\right)$.

In this equation, the flux $F_{\mathrm{O}}$ is a function of the water density $\rho$, the fractional coverage of sea ice (in each grid box) $A$, the "piston velocity" $k$ and the oxygen concentration at saturation point, $\mathrm{O}_{\text {sat }}$. The functional forms of $k$ and $\mathrm{O}_{\text {sat }}$ are now given:

$$
\begin{aligned}
& k=0.31 u^{2} \sqrt{\frac{660}{S c}} \\
& \mathrm{O}_{\mathrm{sat}}=\frac{1000 e^{A}}{22.3916},
\end{aligned}
$$

where $u$ is the wind speed and $S c$ is the Schmidt number (Keeling et al., 1998),

$$
S c=1638+T_{\mathrm{c}}\left(-81.83+T_{\mathrm{c}}\left(1.483-0.008004 T_{\mathrm{c}}\right)\right),
$$

and $A$ ( $\ln C_{0}$ in Garcia and Gordon, 1992) is given by

$$
\begin{aligned}
A & =2.00907+3.22014 T_{\mathrm{s}}+4.05010 T_{\mathrm{s}}^{2}+4.94457 T_{\mathrm{s}}^{3} \\
& -0.256847 T_{\mathrm{s}}^{4}+3.88767 T_{\mathrm{s}}^{5}+H\left(-6.24523 \times 10^{-3}\right. \\
& -7.37614 \times 10^{-3} T_{\mathrm{s}}+1.03410 \times 10^{-2} T_{\mathrm{s}} \\
& \left.-8.17083 \times 10^{-3} T_{\mathrm{s}}^{3}\right)-4.88682 \times 10^{-7} S^{2} .
\end{aligned}
$$

In these equations, $T_{\mathrm{c}}$ and $T_{\mathrm{s}}$ are given by

$T_{\mathrm{c}}=\max (-2, \operatorname{MIN}(40, T+273.15))$

and

$T_{\mathrm{S}}=\ln \left(\left(\frac{5.713}{\operatorname{MAX}(2.71,0.01(273.15+T))}\right)-1\right)$,

where $T$ is the temperature in degrees Celsius and $S$ is the salinity in practical salinity units (PSU). Note that Eq. (7) is from the text in Garcia and Gordon (1992) immediately following their Eq. (8), and that a minimum temperature of $-2.15^{\circ}$ has been imposed to prevent divergence resulting from a vanishing denominator. It should also be noted that Eq. (8) in Garcia and Gordon (1992) contains an error, which is corrected in the OCMIP protocols and therefore in our code (Najjar and Orr, 1999). Finally, the air-sea boundary condition is given by

$\frac{\mathrm{dO}}{\mathrm{d} t}=\frac{F_{\mathrm{O}}}{\Delta z_{1}}$,

where $\Delta z_{1}$ is the depth of the first level in the ocean GCM vertical grid. In the preceding equations, the units are as follows: $\mathrm{O}_{\text {sat }}\left(\mathrm{Mol} \mathrm{m}^{-3}\right), k\left(\mathrm{~m}^{2} \mathrm{~s}^{-2}\right)$ and $S c, A$ and $T_{\mathrm{s}}$ are dimensionless.

All the results presented in this work are from a 3500year integration using a fixed atmospheric $\mathrm{CO}_{2}$ loading of 

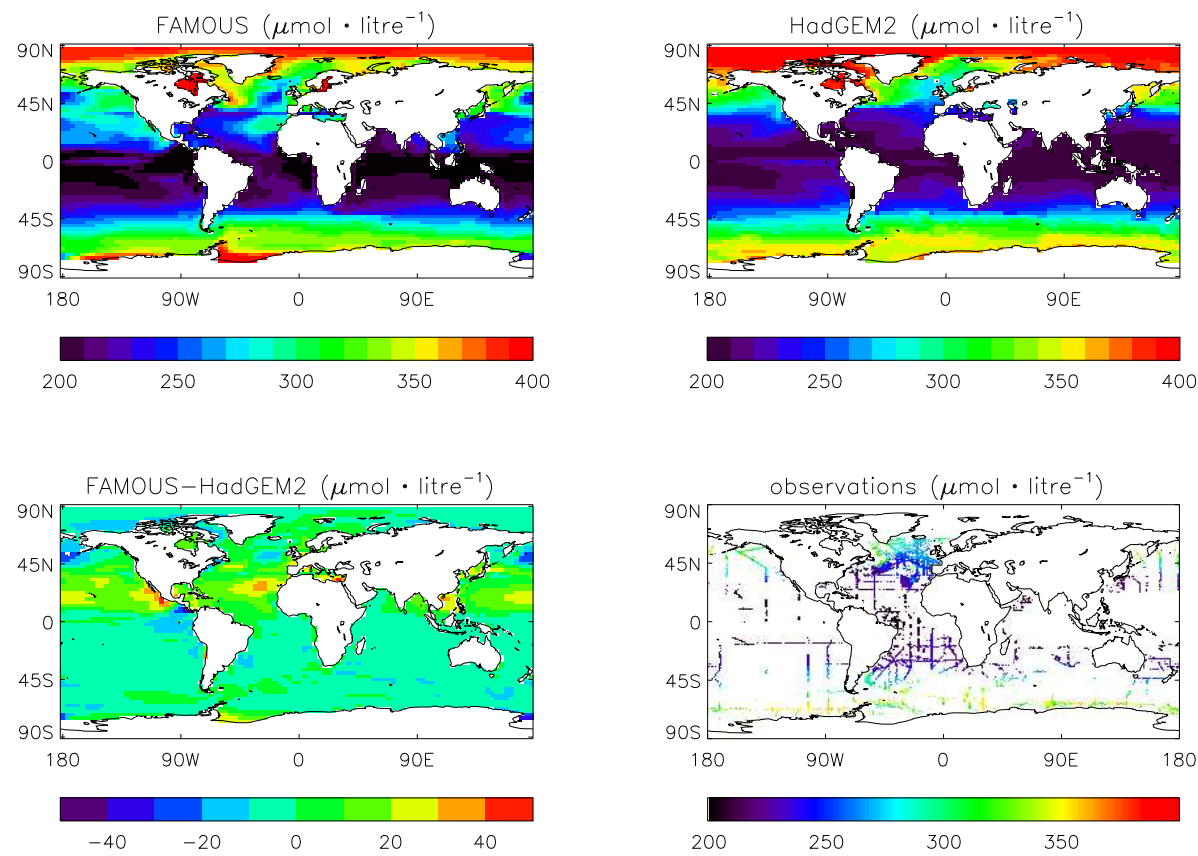

Figure 1. Surface oxygen concentrations $\left(\mu \mathrm{mol} \mathrm{kg}{ }^{-1}\right.$ ) for FAMOUS (top left) and HadGEM2-ES (top right). The percentage difference between the two is shown in the bottom left panel and the paucity of observations (Helm et al., 2011) is illustrated in the bottom right panel.

290 parts per million (ppm). The results therefore are representative of preindustrial boundary conditions. The boundary condition files used for initialising the simulation are themselves the result of an equilibrated simulation and therefore the results presented here can be considered as equilibrated as possible. This simulation uses dynamic vegetation, a complex land-surface exchange scheme and a fully dynamic NPZD (nutrient, phytoplankton, zooplankton, detritus) ocean carbon cycle. Detailed model setup information can be found Williams et al. (2013), which describes the perturbed physics optimisation process used for obtaining the models' terrestrial and oceanic carbon cycle parameters.

In the next section, agreement between FAMOUS and HadGEM2-ES is described. The horizontal resolution of the ocean GCM in HadGEM2-ES is $1^{\circ}$ in the east-west plane. The same is true in the north-south plane but only between the poles and $30^{\circ}$ from where the resolution increases to $0.33^{\circ}$ on the equator. FAMOUS has a global grid spacing of $2.5^{\circ} \times 3.75^{\circ}$ and therefore has almost an order of magnitude reduction in areal resolution. HadGEM2-ES also has twice as many levels in the vertical (40) compared to FAMOUS (20).

\section{Validation}

FAMOUS was originally developed to act as an intermediary between complex (and slow running) fully coupled GCMs and fast running (but low complexity) Earth Models of Intermediate Complexity (EMICS). The original reason for the simulator moniker is best quoted from the original
FAMOUS documentation paper of Jones et al. (2005): "Basing FAMOUS on HadCM3 means its results are directly traceable to the state-of-the-art model used for policyrelevant climate projections".

Since the addition of an oxygen cycle to the ocean component of FAMOUS represents a completely new addition to the FAMOUS model (and HadCM3 family) it was deemed appropriate to compare the newly obtained climate model output to equivalent data from HadGEM2-ES, the main climate model used by the Met Office Hadley Centre in their submission to the Intergovernmental Panel Climate Change's fifth assessment report. These data are freely available online from the Programme for Climate Model Diagnosis and Intercomparison at http://pcmdi9.1lnl.gov/esgf-web-fe/.

Figure 1 shows the predicted surface oxygen concentrations for FAMOUS and HadGEM2-ES as well as the observational data from Helm et al. (2011) (note that from this paper the 1970 oxygen climatology is used). This observational data set is used due to its recent use in validating the oxygen dynamics of HadGEM2-ES under climate change (Andrews et al., 2013) and hence preserves the traceability of the model development process.

In Fig. 1, the main areas of non-negligible disagreement occur on the Antarctic coast, to the west of equatorial South America and northern mid-latitudes. In spite of these differences, the agreement between the two models is very encouraging, especially when the large disparity in overall model complexity and resolution is taken into account. The bottom right panel in Fig. 1 illustrates the scarcity of surface observations in the Helm et al. (2011) data set and hence why 

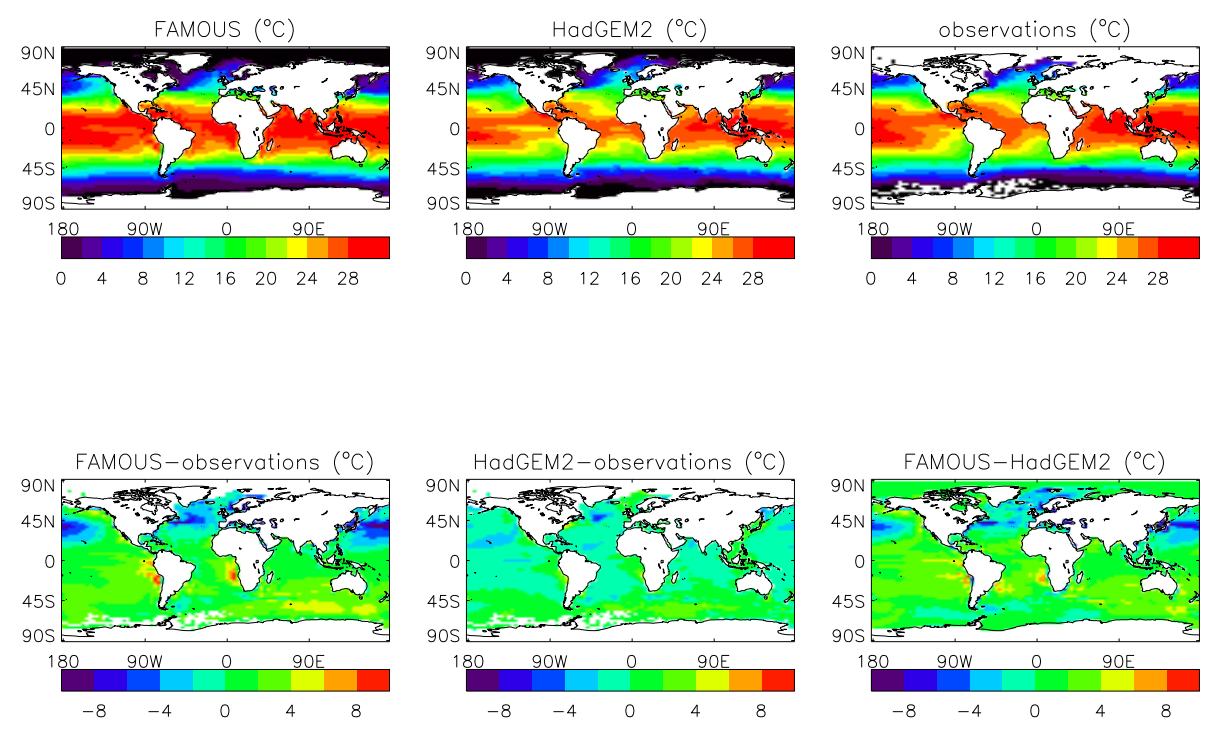

Figure 2. SSTs for FAMOUS (top left), HadGEM2-ES (top middle) and Helm et al. (2011) observations (top right). Difference plots between the models and observations are shown in the bottom left and middle left panels and the difference between the models themselves is shown in the bottom right.

the observations are not a useful benchmark for this latitudelongitude comparison.

Oxygen solubility is a strong negative function of temperature as is evident from Fig. 1 which shows (almost zonally symmetric) high values at the poles and lower values at the equator. It is therefore instructive to consider the sea surface temperature (SST) structure of the models and observations. This is shown in Fig. 2. The observational data set is the 1965-1975 decadal mean from Rayner et al. (2003). This meaning period has been used so that the best match with the 1970 oxygen climatology can be obtained. It should be noted however that in this analysis decadal mean SSTs from 1870 to 1880 right up to the present day have been used and the results obtained are qualitatively identical although clearly there are some minor regional differences.

The most striking aspect of the temperature difference between FAMOUS and HadGEM2-ES in Fig. 2 is the consistent underestimation of Northern Hemisphere SSTs. This is in agreement with the previously noted (e.g. Williams et al., 2013) Northern Hemisphere cold bias in FAMOUS. Due to the negative correlation between temperature and oxygen solubility, it is expected that the surface oxygen concentration in this region in FAMOUS will generally be higher than in HadGEM2-ES and this is indeed seen in Fig. 1. Clearly there are other effects on surface oxygen concentration such as advection and diffusion of water masses and consumption and generation of oxygen through biogeochemical processes in the surface waters, and these processes are considered below. However, the general pattern seen here is in line with first-order thermodynamic expectations.

The statistical relationship between simulated and observed surface oxygen concentrations is studied by sampling only the data points in Fig. 1 where observational data from Helm et al. (2011) are present. These plots are shown in Fig. 3.

From Fig. 3 it is clear that FAMOUS generally overestimates the observed values. The average value of this difference is $14.5 \pm 25.5 \mu \mathrm{mol} \mathrm{L}^{-1}$ where the error estimate is one standard deviation $(\sigma)$. The equivalent value for HadGEM2ES vs. observations is $8.3 \pm 17.7 \mu \mathrm{mol} \mathrm{L}^{-1}$ and therefore HadGEM2-ES not only gives a closer fit to the observed values but a more consistently varying one (i.e. lower standard deviation). The comparison of FAMOUS and HadGEM2-ES gives a value of $6.2 \pm 28.1 \mu \mathrm{mol} \mathrm{L}^{-1}$ (FAMOUS greater than HadGEM2-ES).

Figure 2 shows that there are some regions where the models' representation of SST differ significantly and so it is of interest to consider only areas where the models are in relative agreement. To this end the data have been further sub-sampled to include only areas where the models disagree by $2{ }^{\circ} \mathrm{C}$ or less. The value for the comparison between FAMOUS and observations is now $9.9 \pm$ $24.7 \mu \mathrm{mol} \mathrm{L}^{-1}$, i.e. a decrease of $32 \%$ in the average difference but only a marginal decrease in the variability. The results for HadGEM2-ES compared to observations are now $8.2 \pm 17.4 \mu \mathrm{mol} \mathrm{L}^{-1}$ which are virtually unchanged with respect to previous results. This value of $2{ }^{\circ} \mathrm{C}$ was chosen because it is the width of the colour contours in Fig. 2. However, choosing either 1 or $3^{\circ} \mathrm{C}$ to make this point does not change the conclusion reached.

The improved agreement between FAMOUS and observations in these sub-sampled data simply shows that when FAMOUS agrees with HadGEM2-ES, it also agrees better with observations. This is simply a reflection of the better 

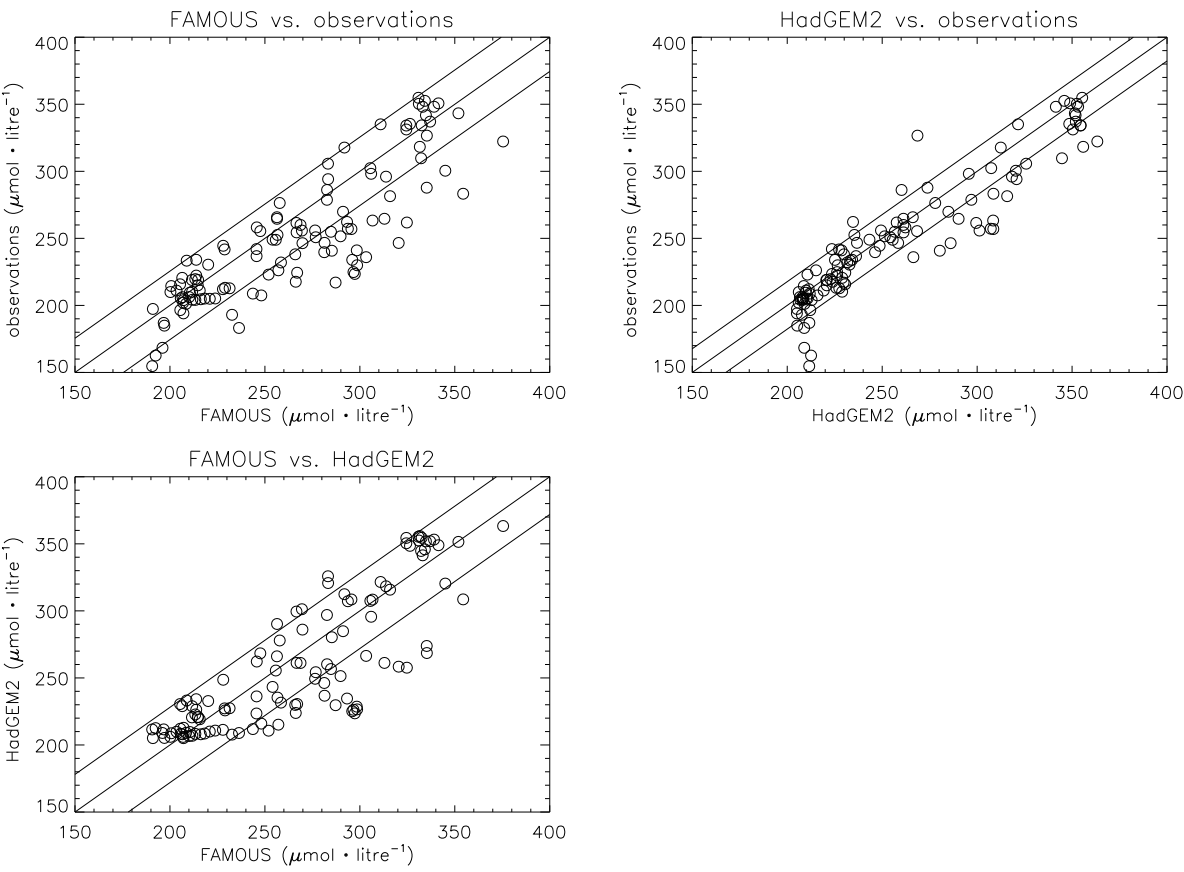

Figure 3. Scatter plots showing the relationships between simulated and observed (Helm et al., 2011) surface oxygen concentrations. Data have been sampled so that only data points where observational data are available are shown (Fig. 1, bottom right). The three lines show the $1: 1$ line and \pm 1 standard deviation $(1 \sigma)$ of the difference between the two quantities.

agreement of HadGEM2-ES with observations in the first place. The essentially unchanged results in the HadGEM2ES comparison with observations are further proof of this fact, i.e. the points which are discarded in this secondary analysis represent points which are indicative of FAMOUS' lack of agreement with observations. Whilst this analysis does give results which are intuitively correct, the highly sparse nature of oxygen observations (Fig. 1) makes this analysis of model agreement with observations virtually impossible "by eye". The same point holds for the SST data (which are also sparse for this time period, as mentioned above) although they are presented in an interpolated format in the Rayner at al. (2003) data set.

Figure 4 shows the comparison in a zonal mean-depth sense where the observations can provide a useful target for validation. The observed oxygen data in Fig. 4 have a vertical resolution of $50 \mathrm{~m}$ throughout the water column.

Firstly, considering the agreement between the models, it is clear that, qualitatively, the oxygen structure of FAMOUS is in good agreement with HadGEM2-ES although the oxygen maxima at high northern latitudes are somewhat underestimated in FAMOUS.

The main area of disagreement in Fig. 4 - both between the models and between the respective models and the observations - is at depth in the Southern Hemisphere where FAMOUS significantly underestimates the oxygen concentration.

To examine this issue further, it is necessary to consider both the continuity (i.e. oxygen "amount") of sinking organic matter in the model as well as the ocean overturning because this will ultimately affect whether or not surface oxygen will be transported to depth. Both of these effects are now considered in turn. Equation (9) is from Palmer and Totterdell (2001) and gives the concentration of detritus as a function of time:

$$
\begin{aligned}
\left.\frac{\partial D}{\partial t}\right|_{\text {biology }} & =m_{D} P^{2}+\frac{1}{3}\left(\mu_{1} Z+\mu_{2} Z^{2}\right) \\
& +E_{D}-\lambda D-G_{\mathrm{d}},
\end{aligned}
$$

where

$m_{D}=m \cdot \min \left(1, \frac{C_{\mathrm{p}}}{C_{\mathrm{d}}}\right)$

and

$$
\begin{aligned}
& E_{D}= \\
& \min \left(\left(G_{\mathrm{p}}+G_{\mathrm{d}}-G_{\mathrm{z}}\right), \frac{\left(C_{\mathrm{p}} G_{\mathrm{p}}+C_{\mathrm{d}} G_{\mathrm{d}}-C_{\mathrm{z}} G_{\mathrm{z}}\right)}{C_{\mathrm{d}}}\right) .
\end{aligned}
$$

In these preceding three equations, $D, P$ and $Z$ are the detritus, phytoplankton and zooplankton concentrations, $m_{D}$ is the phytoplankton mortality rate constant, $\mu_{1,2}$ are the constant and zooplankton-dependent mortality coefficients, $E_{D}$ is the rate of detritus formation due to egestion, $\lambda$ is the (depth dependent) remineralisation rate, $G_{\mathrm{Z}}$ is the zooplankton grazing rate, $C_{\mathrm{p}, \mathrm{z}, \mathrm{d}}$ are the carbon : nitrogen ratios in phytoplankton, zooplankton and detritus and $G_{\mathrm{d}, \mathrm{p}}$ are the 

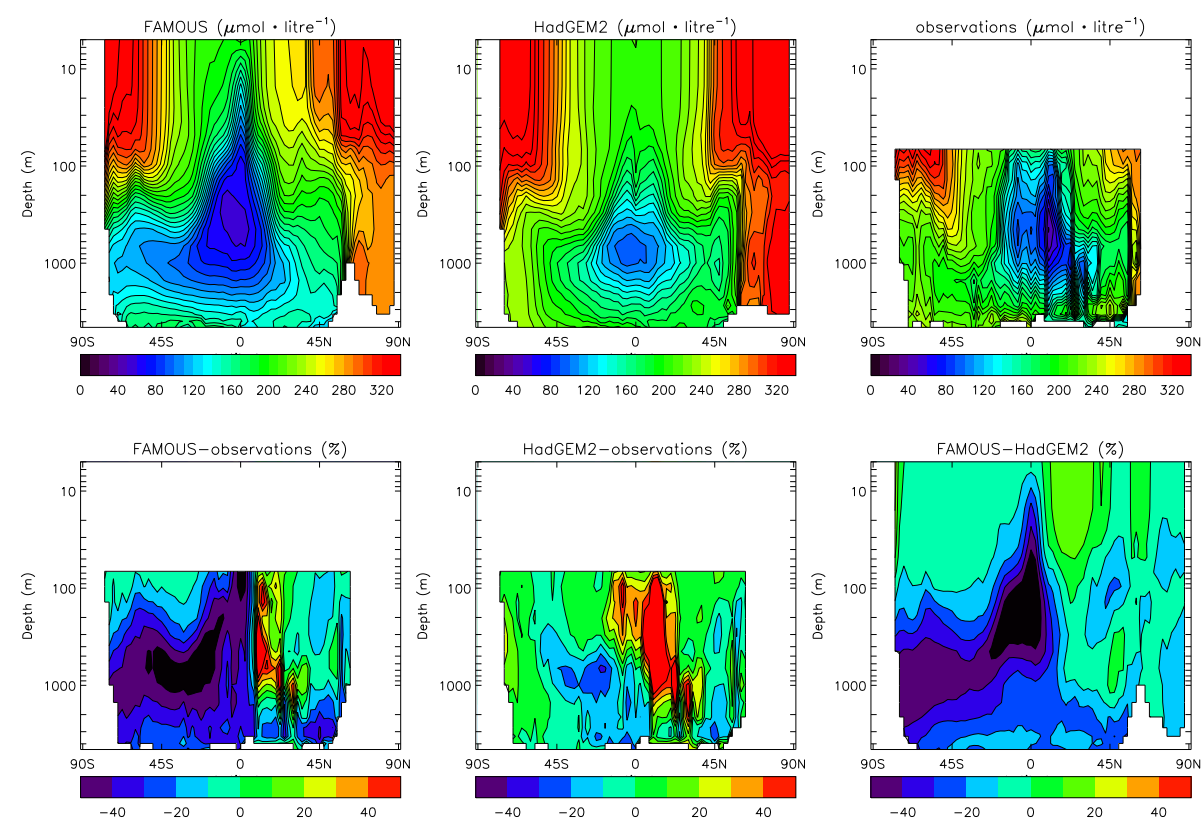

Figure 4. Zonal mean-depth oxygen concentrations ( $\mu \mathrm{mol} \mathrm{L}^{-1}$ ) for FAMOUS (top left), HadGEM2-ES (top middle) and Helm et al. (2011) observations (top right). Percentage difference plots between the models and observations are shown in the bottom left and middle left panels and the difference between the models themselves is shown in the bottom right.

grazing rates of zooplankton on detritus and phytoplankton respectively. Finally,

$m= \begin{cases}0, & P \leq 0.01 \mu \mathrm{mol} \mathrm{L}-1 \\ m_{0}, & \text { otherwise },\end{cases}$

where $m_{0}$ is the mortality rate of phytoplankton.

Figure 5 shows the surface net primary productivity (NPP) for FAMOUS and HadGEM2-ES compared to available observations (Behrenfeld and Falkowski, 1997).

Figure 5 clearly shows that both models overestimate equatorial NPP. This overestimation is largest in the Pacific and is significantly larger in FAMOUS. This behaviour has been noted previously in Williams et al. (2013) where the current setup of FAMOUS was compared to previous incarnations. The tuning target in the perturbed-physics ensembles in Williams et al. (2013) was the surface nitrate concentration, not NPP. It is likely that if NPP had been used instead that this significant equatorial bloom would have been less marked. This spike in productivity will lead to an increased amount of detritus sinking out of the photic zone (top few hundred metres) of the ocean which will then undergo remineralisation. This is qualitatively the reverse of photosynthesis and therefore consumes oxygen, hence reducing the oxygen content.

The agreement between simulated and observed oxygen concentration is now examined on the basin scale in Figs. 6 and 7 using the spatially complete World Ocean Atlas (2009) database (Garcia et al., 2010). It is particularly clear from Fig. 7 that the globally prevalent positive bias in both FAMOUS and HadGEM2-ES (Fig. 4) between $\approx 100$ $1000 \mathrm{~m}$ at low northern latitudes can be attributed to the Pacific Ocean where the same characteristic "U"-shaped positive bias is evident in both models. Using the reverse of the argument given above, this can be attributed to both models' underestimation of NPP at mid-to-high latitudes. In Fig. 7, FAMOUS' pronounced equatorial oxygen minimum can be seen to be due to the equally pronounced NPP maximum at this location. It should be noted here that although a different data set is used for this part of the analysis, Figs. 6 and 7 have been replotted (not shown) and no significant differences between them was noted. Indeed, as stated above, the reason why the Helm et al. (2011) data set was chosen in the first place was to maintain model development traceability with Andrews et al. (2013). It should also be noted that although the World Ocean Atlas oxygen data set does provide a full latitude-longitude data set, the observations that enter into it are still sparse, as can be seen from Fig. 8. Indeed it is clear from this figure that although the North Atlantic sector's coastal regions, the west coast of America and also Japan have very good coverage, significant areas of the world are very poorly sampled - for example virtually the entire Southern Hemisphere.

With regard to FAMOUS' underestimation of Southern Hemisphere oxygen shown in Fig. 4, Figs. 6 and 7 show that this is due to a basin-scale underestimation in both the Atlantic and Pacific, which can be tied to the NPP blooms just to the south of the equator in both basins. In the southern Pacific Ocean in HadGEM2-ES there is generally good 

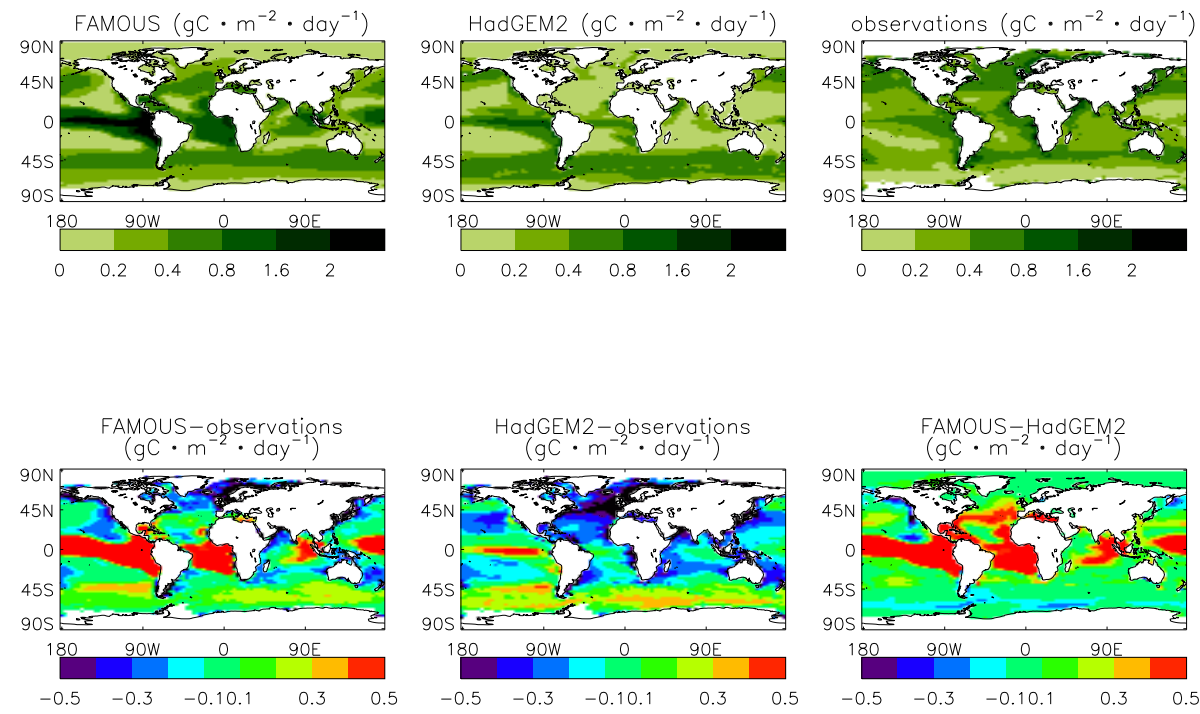

Figure 5. Net primary productivity (NPP) $\left(\mathrm{gC} \mathrm{m}^{-2} \mathrm{day}^{-1}\right)$ for FAMOUS (top left), HadGEM2-ES (top middle) and observations (top right). Absolute difference plots between the models and observations are shown in the bottom left and middle left panels and the difference between the models themselves is shown in the bottom right.

agreement between observed and simulated NPP and oxygen fields.

The first-order connection between increased (decreased) NPP and decreased (increased) oxygen concentrations holds well throughout this analysis with the only notable exception being the northern Atlantic basin in HadGEM2-ES. In this region, HadGEM2-ES significantly underestimates observed NPP yet has a generally good representation of oxygen.

As stated above, the amount of oxygen produced and consumed is one factor in a dynamic system's behaviour, but for a full understanding, the transport must also be considered. Equation (13) shows the three-dimensional continuity equation for a generic density $\rho$ and velocity vector field $\boldsymbol{u}$ :

$$
\frac{\partial \rho}{\partial t}+\nabla \cdot(\rho \boldsymbol{u})+G_{\mathrm{O}}^{+}-G_{\mathrm{O}}^{-}=0
$$

where $G_{\mathrm{O}}^{+}$and $G_{\mathrm{O}}^{-}$represent generation and consumption of oxygen due to, for example, photosynthesis and remineralisation. Figures 9 and 10 show the meridional overturning circulation (MOC) in sverdrups (millions of cubic metres per second) for FAMOUS and HadGEM2-ES in the global and Atlantic oceans respectively (note the different latitude limits in the two figures).

From Fig. 9, it is clear that FAMOUS significantly underestimates the circulation seen in HadGEM2-ES and also fails to reproduce the observed global "two cell" meridional overturning circulation pattern (for example, Fig. 2 in Lumpkin and Speer, 2007). Assuming that this circulation has an important effect on the oxygen concentration through reduced ventilation, the significantly reduced Southern Hemisphere circulation in FAMOUS compared to HadGEM2-ES should result in a large decrease in the oxygen concentration in this region, which is indeed seen in Fig. 4.

From a more quantitative angle, the overturning on the basin scale is now interrogated. Kanzow et al. (2010) have given an observed value of $18.7 \pm 2.7 \mathrm{~Sv}$ for the maximum absolute value of the Atlantic basin overturning at $26.5^{\circ} \mathrm{N}$. For the four HadGEM2-ES realisations studied here (the results presented above are the ensemble mean) a value of $12.7 \pm 0.6 \mathrm{~Sv}$ is found and for FAMOUS, $12.7 \pm 0.4 \mathrm{~Sv}$. The uncertainty estimate in FAMOUS is obtained by calculating the overturning for the last four 30-year periods of a 3500year run. These figures are in agreement with previously published data on HadGEM2-ES from the HadGEM2 Development Team (2011), $\left(13.3 \pm 1.0 \mathrm{~Sv}\right.$ at $26^{\circ} \mathrm{N}$ for a preindustrial simulation) but are weaker than the 2004-2008 estimate of Kanzow et al. (2010) given above and the HadGEM2-ES figures for the period $1990-2000\left(16.0 \pm 1.0 \mathrm{~Sv}\right.$ at $\left.30^{\circ} \mathrm{N}\right)$ from the HadGEM2 Development Team (2011).

Figure 10 shows that HadGEM2-ES has well-developed upper and lower circulatory cells which are analogous to the (upper) North Atlantic Deep Water (NADW) and (lower) Antarctic Bottom Water (AABW) systems observed in Talley et al. (2003). This AABW water cell in the Atlantic basin is not present in FAMOUS. This shows that Southern Hemisphere water is not being circulated into northern latitudes and hence that the general circulation in this region is more sluggish than HadGEM2-ES and adds further evidence that the circulation in FAMOUS is being underestimated compared to HadGEM2-ES.

A separate study is currently underway to improve the physical circulation in FAMOUS via statistical selection of transport parameters which will be reported in a future paper. 

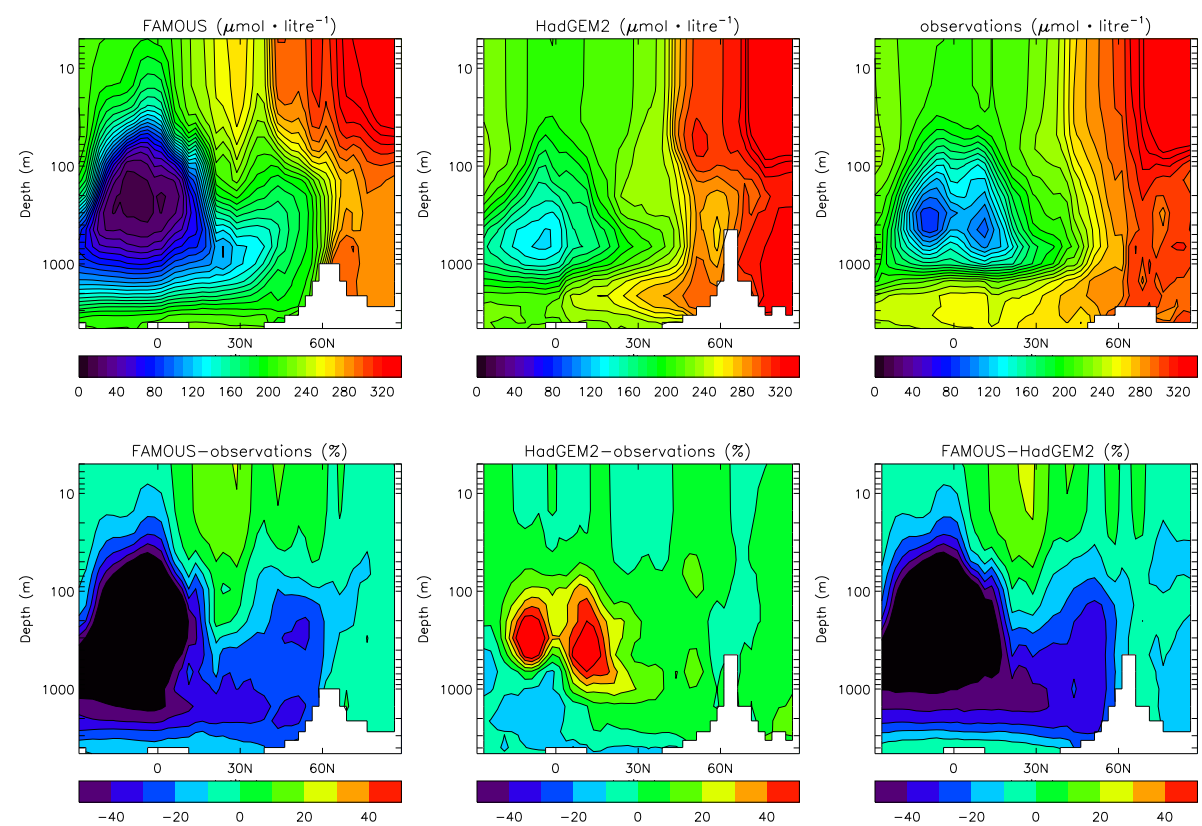

Figure 6. Zonal mean-depth oxygen concentrations for the Atlantic ( $\mu \mathrm{mol} \mathrm{L}^{-1}$ ) for FAMOUS (top left), HadGEM2-ES (top middle) and World Ocean Atlas observations (top right). Percentage difference plots between the models and observations are shown in the bottom left and middle left panels and the difference between the models themselves is shown in the bottom right. The same contour levels as Fig. 4 are deliberately used here and hence the bottom left and bottom right figures show colour saturation due to the evident disagreement. The minimum values are -89 and $-92.1 \%$ in the left and right cases respectively.
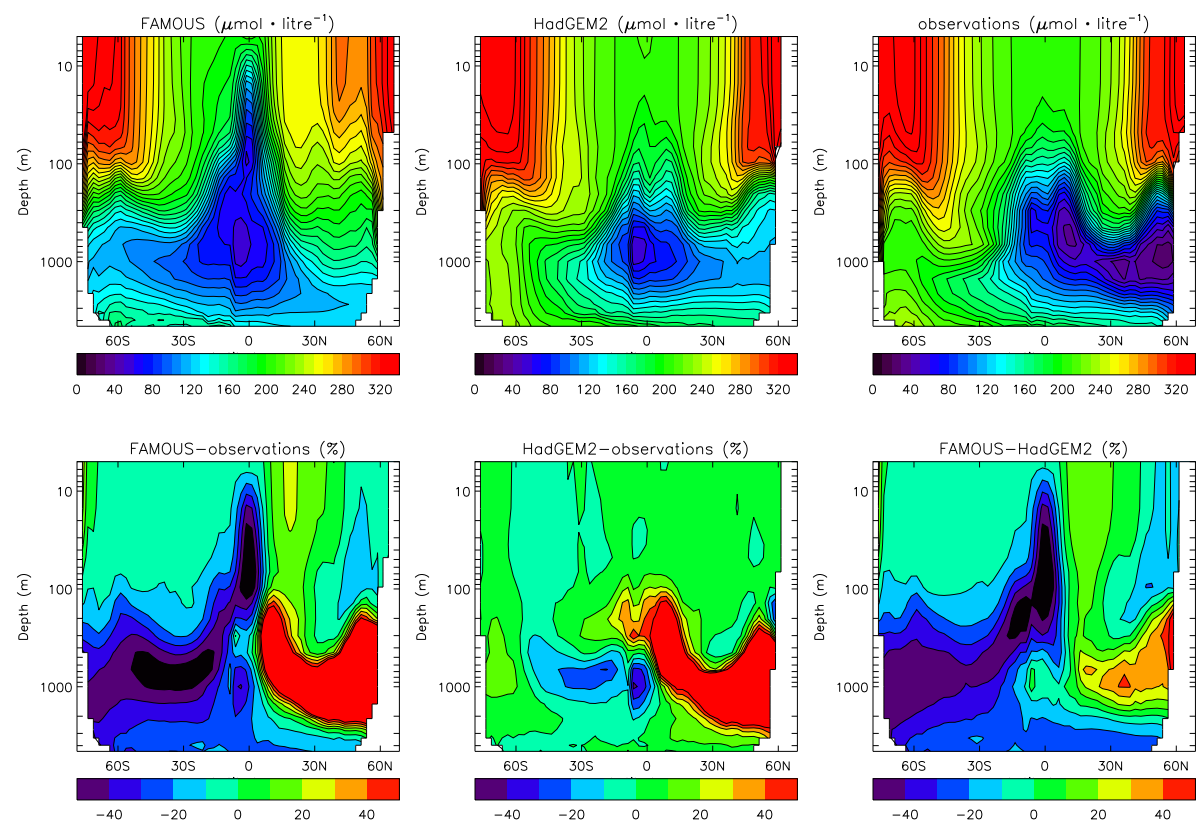

Figure 7. Zonal mean-depth oxygen concentrations for the Pacific ( $\mu \mathrm{mol} \mathrm{L}^{-1}$ ) for FAMOUS (top left), HadGEM2-ES (top middle) and World Ocean Atlas observations (top right). Percentage difference plots between the models and observations are shown in the bottom left and middle left panels and the difference between the models themselves is shown in the bottom right. 


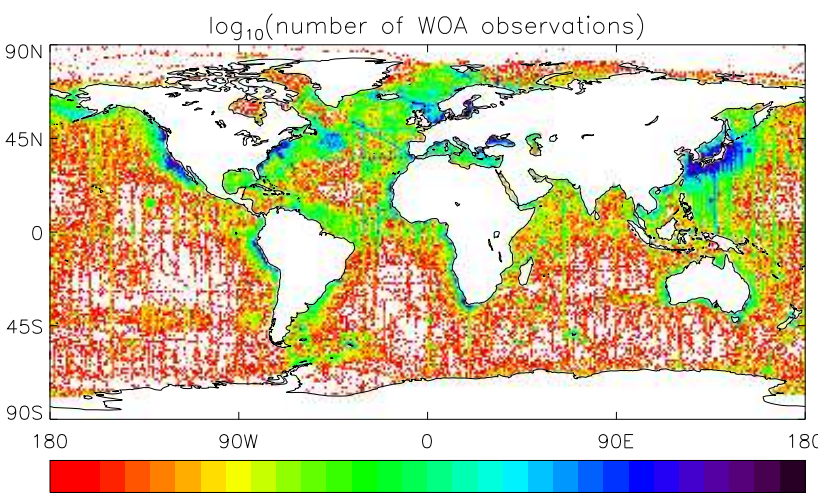

Figure 8. The number of observations making up the World Ocean Atlas oxygen climatology (Garcia et al., 2010).

It is hoped that this ongoing work will significantly improve the understanding of deep water formation in the Southern Hemisphere and hence also improve the agreement with observations of oxygen content. FAMOUS has a dynamic sea ice model and static ice sheets over Antarctica and since cryospheric processes have a strong influence on deep water formation, simulations of warm past climates are expected to yield more useful representations of deep water masses due to their lack of permanent ice on land or at sea (e.g. MacLeod et al., 2013). In contrast to the lack of agreement between simulated and observed values at depth, it is clear from Fig. 1 that FAMOUS can provide a good reproduction of the near-surface oxygen distribution predicted by HadGEM2ES. What this means is that FAMOUS could be used to study long-term future climate scenarios where ocean warming is predicted to exacerbate the already-detected deoxygenation of the oceans due to climate change (e.g. Andrews et al., 2013). These future scenarios should be confined to surface waters due to the already-mentioned issues with the model reproduction of observed oxygen at depth. However, it is only in the first $\approx 100 \mathrm{~m}$ where light can penetrate far enough to stimulate primary production and hence serve as the base of the ocean food chain.

Now, considering the Atlantic basin as a whole, the numerical information of Talley et al. (2003) is given in Table 1 along with the data for $26.5^{\circ} \mathrm{N}$ given above (note that Fig. 10 gives the maximum Atlantic overturning value for FAMOUS at approximately $26^{\circ} \mathrm{N}$ ). The lower value for FAMOUS compared to HadGEM2-ES is in agreement with the results noted above, i.e. that the circulation in FAMOUS is generally more sluggish than HadGEM2-ES. The fact that both models underestimate the value of $18 \mathrm{~Sv}$ given by Talley et al. however should be tempered by the fact that the authors give an error estimate of between 3 and $5 \mathrm{~Sv}$ on their circulation magnitudes.

For completeness, the circulation pattern in the Pacific basin is now considered and is shown in Fig. 11. As has been previously shown for the Atlantic basin, the circulation in the
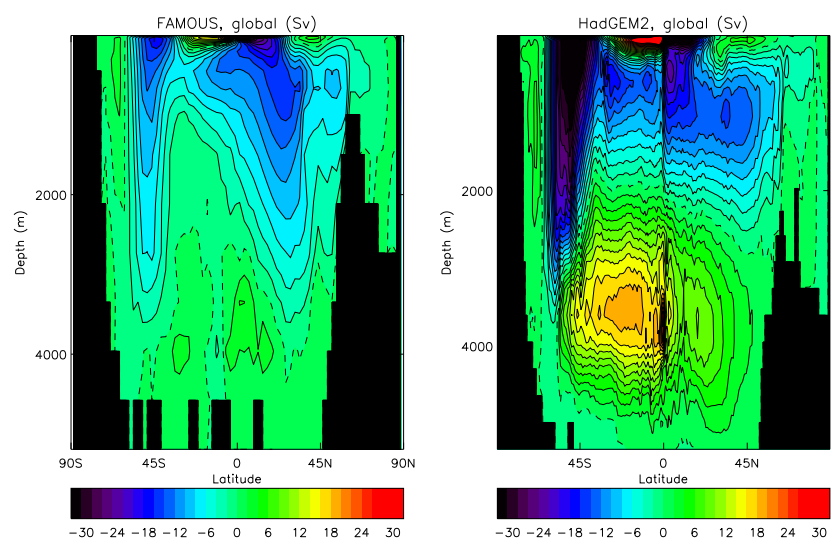

Figure 9. Global meridional overturning circulation (MOC) in FAMOUS (left) and HadGEM2-ES (right). The zero contour is dashed.
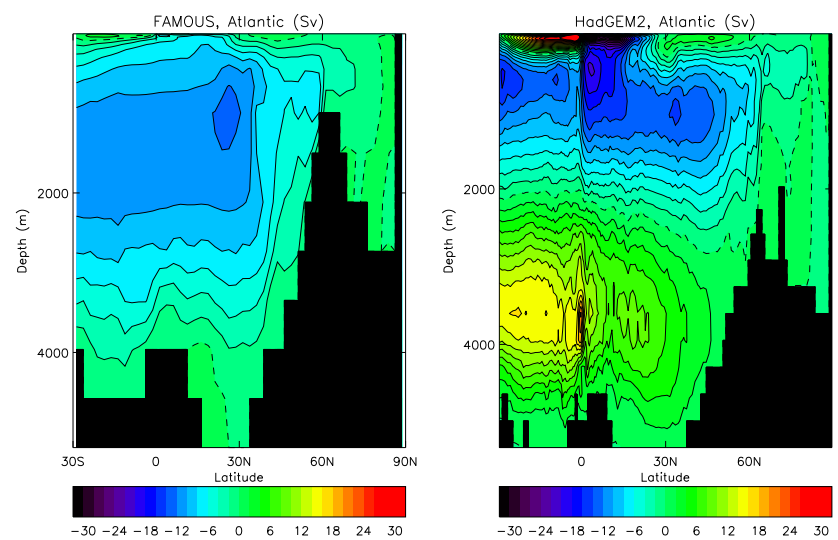

Figure 10. Atlantic meridional overturning circulation (MOC) in FAMOUS (left) and HadGEM2-ES (right). The zero contour is dashed.
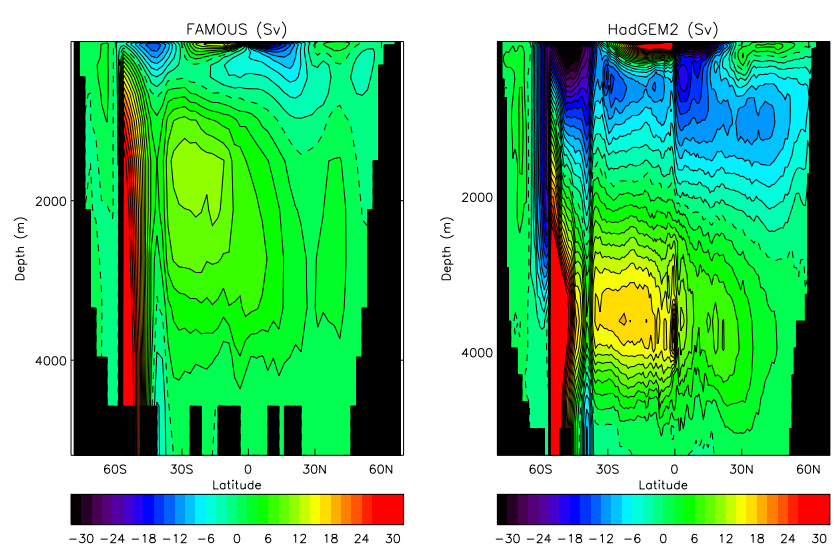

Figure 11. Pacific meridional overturning circulation (MOC) in FAMOUS (left) and HadGEM2-ES (right). The zero contour is dashed. 
Table 1. Atlantic meridional overturning circulation (AMOC) in Sv for the Atlantic on the basin scale (lower line) and specifically at $26.5^{\circ} \mathrm{N}$ (upper line). Note the lack of an error estimate for the Talley et al. (2003) figures. The authors of this paper note "Uncertainty in the diagnosed streamfunction is large, on the order of 3-5 Sv".

\begin{tabular}{lcccc}
\hline & FAMOUS & HadGEM2-ES & Kanzow et al. (2010) & Talley et al. (2003) \\
\hline Atlantic $\left(26.5^{\circ} \mathrm{N}\right)$ & $12.7 \pm 0.4$ & $12.7 \pm 0.6$ & $18.7 \pm 2.7$ & - \\
Atlantic (basin scale) & $12.7 \pm 0.4$ & $15.0 \pm 0.9$ & - & 18 \\
\hline
\end{tabular}
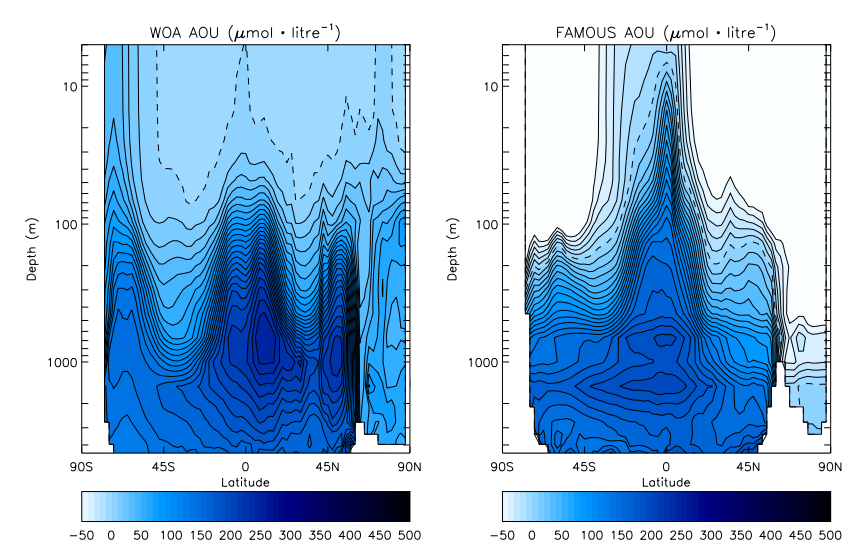

Figure 12. Global apparent oxygen utilisation for World Ocean Atlas observations (left) and for FAMOUS (right). The zero contour is dashed.

Pacific for FAMOUS is noticeably weaker than HadGEM2ES. However, unlike in the Atlantic basin, FAMOUS does show some Southern Hemisphere deep water formation. This may help to explain the reduced (yet still notable) oxygen underestimation in Fig. 7 compared to Fig. 6, i.e. the deep water formation is providing increased pelagic ventilation and hence increased oxygen concentration.

Finally, the apparent oxygen utilisation (AOU) is considered. This is a measure of the biochemically induced deviation of oceanic oxygen from its equilibrium atmospheric concentration (e.g Garcia et al., 2010) and is shown for World Ocean Atlas observations and FAMOUS in Figs. 12-14. As can be seen on a global scale from Fig. 12, FAMOUS has large negative values at the surface, particularly at mid-tohigh latitudes. What this means is that the surface ocean is over-saturated with oxygen. Interestingly, it can also be seen from Fig. 14 that FAMOUS' global structure in Fig. 12 can mostly be attributed to the Pacific. This makes sense because (as can be seen in Fig. 5) although FAMOUS generally overestimates equatorial NPP, the Pacific bias clearly dominates.

Now considering the Atlantic AOU, the correlation between FAMOUS' oxygen concentration (with respect to observations) in Fig. 6 and the AOU in Fig. 13 is striking, particularly in the Northern Hemisphere. What this means is that the AOU in the north Atlantic is significantly too high (large negative values) because of enhanced photosynthesis. However this is being compensated by other processes, for
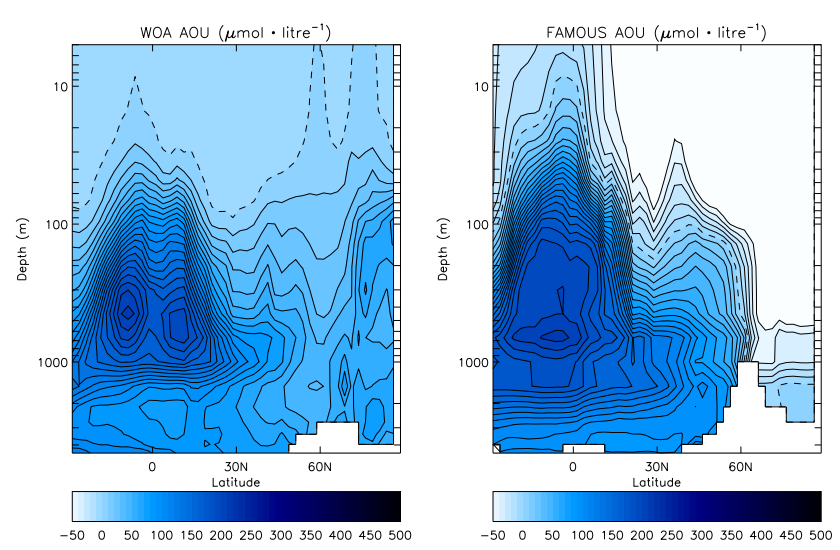

Figure 13. Apparent oxygen utilisation for the Atlantic; World Ocean Atlas observations (left) and for FAMOUS (right). The zero contour is dashed.
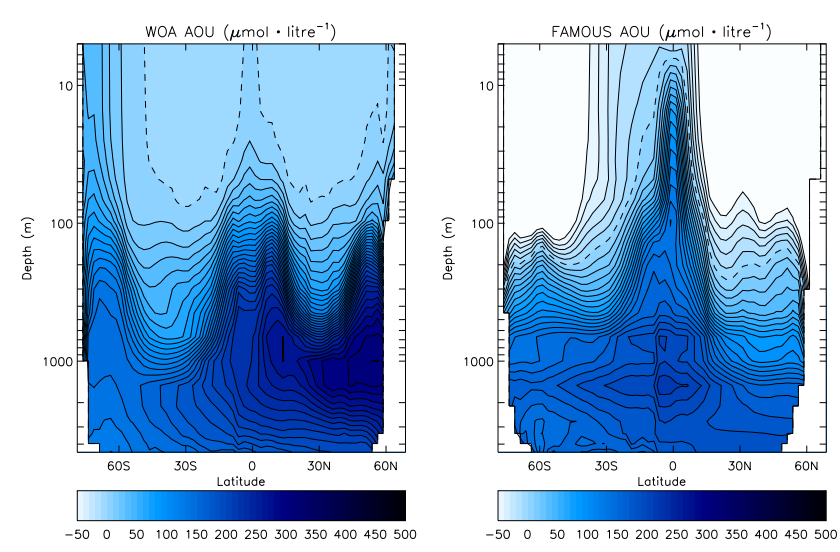

Figure 14. Apparent oxygen utilisation for the Pacific; World Ocean Atlas observations (left) and for FAMOUS (right). The zero contour is dashed.

example the lack of deep water mixing (Fig. 10). This compensation of one process being overestimated and (at least) one being underestimated combine to give good agreement at high northern latitudes (Fig. 6).

As is the case with any climate simulation framework, there are many processes missing from the oxygen scheme presented here, due to time and computational constraints. Examples of these include the fact that surface waters will not necessarily be properly equilibrated with the atmosphere at all times and places (Garcia et al., 2010) and, perhaps more 
fundamentally in this example, that the oxygen scheme described here is an addition to a pre-existing NPZD model. This can, for example, be contrasted to the Darwin model (e.g. Vallina et al., 2014) which can represent not only many functional forms of plankton but also their adaptation to environmental niches.

\section{Conclusions}

This paper describes an update to the latest version of FAMOUS (Williams et al., 2013) in which a numerically calculated oxygen cycle is included for the first time. This follows the scheme of the latest Hadley Centre GCM, HadGEM2-ES, under the auspices of the second phase of the Ocean CarbonCycle Model Intercomparison Project, OCMIP2. The surface oxygen concentration is in good agreement with that of HadGEM2-ES. FAMOUS' general overestimation of the Northern Hemisphere surface oxygen concentration is attributed to its underestimation of SST. When the model output is compared against available surface observations on a point-by-point basis, both models generally overestimate the observed values, although this overestimation is reduced in HadGEM2-ES.

The agreement between the simulated oxygen concentrations at depth in the Northern Hemisphere is also encouraging. The deep Southern Hemisphere agreement is less good however.

The notable disagreement between oxygen concentrations at depth in the Southern Hemisphere is partially ascribed to FAMOUS' overestimation of equatorial net primary productivity which causes increased remineralisation of sinking detritus at depth and hence increased oxygen consumption. This is further exacerbated by reduced ocean circulation in FAMOUS compared to HadGEM2-ES which acts to reduce Southern Hemisphere ventilation. This reduction in circulatory strength is evident in both the global and Atlantic oceans. To aid regional understanding in this regard, meridional overturning circulation, oxygen concentrations and apparent oxygen utilisation (AOU) have been studied on the basin scale. Examples of the utility of this include the attribution of Northern Hemisphere, intermediate depth overestimation of oxygen in both HadGEM2-ES and FAMOUS to the Pacific and also give an explanation of why equatorial blooms of NPP seem to affect the deep oxygen concentration in the Southern Hemisphere more than in the Northern Hemisphere in FAMOUS.

Finally, the authors feel that with recent developments in the terrestrial and oceanic carbon cycles and now with the introduction of oceanic oxygen, the FAMOUS model is leaving the traditional "climate model" definition and moving into the realm of an "Earth-System model" - hence the title of this paper.

\section{Code availability}

The main repository for the Met Office Unified Model (UM) at the version corresponding to the model presented here can be found at http://cms.ncas.ac.uk/code_browsers/UM4. 5/UMbrowser/index.html.

\section{Supplement}

The code detailing the advances described in this paper is completely contained within one text file (known as a code modification file or "mod") and this is available as a Supplement to this paper. This is protected under Crown Copyright, as is the base code linked above.

\section{The Supplement related to this article is available online at doi:10.5194/gmd-7-1419-2014-supplement.}

Acknowledgements. J. H. T. Williams and P. J. Valdes were supported by funding from Statoil ASA, Norway. J. H. T. Williams and P. J. Valdes thank T. L. Leith of Statoil ASA for extensive discussions throughout this work. I. J. Totterdell and P. R. Halloran were supported by the Joint DECC/Defra Met Office Hadley Centre Climate Programme (GA01101). The authors are grateful to two anonymous reviewers and to the topical editor whose comments and suggestions have significantly improved this paper.

Edited by: G. Munhoven

\section{References}

Andrews, O. D., Bindoff, N. L., Halloran, P. R., Ilyina, T., and Le Quéré, C.: Detecting an external influence on recent changes in oceanic oxygen using an optimal fingerprinting method, Biogeosciences, 10, 1799-1813, doi:10.5194/bg-10-1799-2013, 2013.

Anderson, L. A. and Sarmiento, J. L.: Redfield ratios of remineralization determined by nutrient data analysis, Global Biogeochem. Cy., 8, 65-80, 1994

Behrenfeld, M. J. and Falkowski, P. G.: Photosynthetic rates derived from satellite-based chlorophyll concentration, Limnol. Oceanogr., 42, 1-20, 1997.

Bellouin, N., Rae, J., Jones, A., Johnson, C., Haywood, J., and Boucher, O.: Aerosol forcing in the climate model intercomparison project (CMIP5) simulations by HadGEM2-ES and the role of ammonium nitrate, J. Geophys. Res., 116, D20206, doi:10.1029/2011JD016074, 2011.

Bopp, L., Le Quéré, C., Heimann, M., and Manning, A. C.: Climateinduced oceanic oxygen fluxes: Implications for the contemporary carbon budget, Global Biogeochem. Cy., 16, 6.1-6.13, doi:10.1029/2001GB001445, 2002.

Collins, W. J., Bellouin, N., Doutriaux-Boucher, M., Gedney, N., Halloran, P., Hinton, T., Hughes, J., Jones, C. D., Joshi, M., Liddicoat, S., Martin, G., O’Connor, F., Rae, J., Senior, C., Sitch, 
S., Totterdell, I., Wiltshire, A., and Woodward, S.: Development and evaluation of an Earth-System model - HadGEM2, Geosci. Model Dev., 4, 1051-1075, doi:10.5194/gmd-4-10512011, 2011.

Cox, P. M., Betts, R. A., Jones, C. D., Spall, S. A., and Totterdell, I. J.: Acceleration of global warming due to carbon-cycle feedbacks in a coupled climate model, Nature, 408, 184-187, 2000.

Frölicher, T. L., Joos, F., Plattner, G.-K., Steinacher, M., and Doney, S. C.: Natural variability and anthropogenic trends in oceanic oxygen in a coupled carbon-climate model ensemble, Global Biogeochem. Cy., 23, GB1003, doi:10.1029/2008GB003316, 2009.

Garcia, H. E. and Gordon, L. I.: Oxygen solubility in seawater: better fitting equations, Limnol. Oceanogr., 37, 1307-1312, 1992.

Garcia, H. E., Locarnini, R. A., Boyer, T. P., Antonov, J. I., Baranova, O. K., Zweng, M. M., and Johnson, D. R.: World Ocean Atlas 2009, Volume 3: Dissolved Oxygen, Apparent Oxygen Utilization, and Oxygen Saturation, edited by: Levitus, S., NOAA Atlas NESDIS 70, U.S. Government Printing Office, Washington, D.C., 344 pp., 2010.

Gordon, C., Cooper, C., Senior, C. A., Banks, H., Gregory, J. M., Johns, T. C., Mitchell, J. F. B., and Wood, R. A.: The simulation of SST, sea ice extents and ocean heat transports in a version of the Hadley Centre coupled model without flux adjustments, Clim. Dynam., 16, 147-168, 2000.

The HadGEM2 Development Team: G. M. Martin, Bellouin, N., Collins, W. J., Culverwell, I. D., Halloran, P. R., Hardiman, S. C., Hinton, T. J., Jones, C. D., McDonald, R. E., McLaren, A. J., O'Connor, F. M., Roberts, M. J., Rodriguez, J. M., Woodward, S., Best, M. J., Brooks, M. E., Brown, A. R., Butchart, N., Dearden, C., Derbyshire, S. H., Dharssi, I., Doutriaux-Boucher, M., Edwards, J. M., Falloon, P. D., Gedney, N., Gray, L. J., Hewitt, H. T., Hobson, M., Huddleston, M. R., Hughes, J., Ineson, S., Ingram, W. J., James, P. M., Johns, T. C., Johnson, C. E., Jones, A., Jones, C. P., Joshi, M. M., Keen, A. B., Liddicoat, S., Lock, A. P., Maidens, A. V., Manners, J. C., Milton, S. F., Rae, J. G. L., Ridley, J. K., Sellar, A., Senior, C. A., Totterdell, I. J., Verhoef, A., Vidale, P. L., and Wiltshire, A.: The HadGEM2 family of Met Office Unified Model climate configurations, Geosci. Model Dev., 4, 723-757, doi:10.5194/gmd-4-723-2011, 2011.

Helm, K. P., Bindoff, N. L., and Chrusch, J. A.: Observed decreases in oxygen content of the global ocean, Geophys. Res. Lett., 38, L23602, doi:10.1029/2011GL049513, 2011.

Hewitt, H. T., Copsey, D., Culverwell, I. D., Harris, C. M., Hill, R. S. R., Keen, A. B., McLaren, A. J., and Hunke, E. C.: Design and implementation of the infrastructure of HadGEM3: the nextgeneration Met Office climate modelling system, Geosci. Model Dev., 4, 223-253, doi:10.5194/gmd-4-223-2011, 2011.

Jones, C., Gregory, J., Thorpe, R., Cox, P., Murphy, J., Sexton, D., and Valdes, P.: Systematic optimisation and climate simulations of FAMOUS, a fast version of HadCM3, Clim. Dynam., 25, 189204, 2005.

Kanzow, T., Cunningham, S. A., Johns, W. E., Hirschi, J. J.-M., Marotzke, J., Baringer, M. O., Meinen, C. S., Chidichimo, M. P., Atkinson, C., Beal, L. M., Bryden, H. L., and Collins, J.: Seasonal variability of the Atlantic meridional overturning circulation at $26.5^{\circ} \mathrm{N}$, J. Climate, 23, 5678-5698, 2010.
Keeling, R. F., Stephens, B. B., Najjar, R. G., Doney, S. C., Archer, D., and Hemimann M.: Seasonal variations in the atmospheric $\mathrm{O}_{2} / \mathrm{N}_{2}$ ratio in relation to the kinetics of air-sea gas exchange, Global Biogeochem. Cy., 12, 141-163, 1998.

Lumpkin, R. and Speer, K.: Global ocean meridional circulation, J. Phys. Oceanogr., 37, 2550-2562, 2007.

Macleod, K. G., Huber, B. T., Berrocoso, Á. J., and Wendler, I.: A stable and hot Turonian with glacial $\delta^{18} \mathrm{O}$ excursions is indicated by exquisitely preserved Tanzanian foraminifera, Geology, 41, 1083-1086, 2013.

Martin, G. M., Ringer, M. A., Pope, V. D., Jones, A., Dearden, C., and Hinton, T. J.: The physical properties of the atmosphere in the new Hadley Centre Global Environmental Model (HadGEM1) - Part 1: Model description and global climatology, J. Climate, 19, 1274-1301, 2006.

Matear, R. J., Hirst, A. C., and McNeil, B. I.: Changes in dissolved oxygen in the Southern Ocean with climate change, Geochem. Geophy. Geosy., 1, 1050, doi:10.1029/2000GC000086, 2000.

Monteiro, F. M., Pancost, R. D., Ridgwell, A., and Donnadieu, Y.: Nutrients as the dominant control on the spread of anoxia and euxinia across the Cenomanian-Turonian ocean anoxic event (OAE2): model-data comparison, Paleoceanography, 27, PA4209, doi:10.1029/2012PA002351, 2012.

Najjar, R. G. and Orr, J. C.: Biotic-HOWTO revision 1.7, OCMIP technical document, last edited: 5 October 1999, available at: www.cgd.ucar.edu/oce/OCMIP/HOWTO-Biotic.ps (last access: 6 June 2014), 1999.

Palmer, J. R. and Totterdell, I. J.: Production and export in a global ocean ecosystem model, Deep-Sea Res. Pt. I, 48, 1169-1198, 2001.

Peña, M. A., Katsev, S., Oguz, T., and Gilbert, D.: Modeling dissolved oxygen dynamics and hypoxia, Biogeosciences, 7, 933957, doi:10.5194/bg-7-933-2010, 2010.

Pope, V. D., Gallani, M. L., Rowntree, P. R., and Stratton, R. A.: The impact of new physical parametrizations in the Hadley Centre climate model: HadAM3, Clim. Dynam., 16, 123-146, 2000.

Rayner, N. A., Parker, D. E., Horton, E. B., Folland, C. K., Alexander, L. V., Rowell, D. P., Kent, E. C., and Kaplan, A.: Global analyses of sea surface temperature, sea ice, and night marine air temperature since the late nineteenth century, J. Geophys. Res., 108, 4407, doi:10.1029/2002JD002670, 2003.

Reichler, T. and Kim, J.: How well do coupled models simulate today's climate?, B. Am. Meteorol. Soc., 89, 303-311, doi:10.1175/BAMS-89-3-303, 2008.

Smith, R. S.: The FAMOUS climate model (versions XFXWB and XFHCC): description update to version XDBUA, Geosci. Model Dev., 5, 269-276, doi:10.5194/gmd-5-269-2012, 2012.

Smith, R. S., Gregory, J. M., and Osprey, A.: A description of the FAMOUS (version XDBUA) climate model and control run, Geosci. Model Dev., 1, 53-68, doi:10.5194/gmd-1-53-2008, 2008.

Talley, L. D., Reid, J. L., and Robbins, P. E.: Data-based meridional overturning streamfunctions for the global ocean, J. Climate, 16, 3213-3226, 2003.

Vallina, S. M., Ward, B. A., Dutkiewicz, S., and Follows, M. J.: Maximal feeding with active prey-switching: A killthe-winner functional response and its effect on global diversity and biogeography, Prog. Oceanogr., 120, 93-109, doi:10.1016/j.pocean.2013.08.001, 2014. 
Webb, M., Senior, C., Bony, S., and Morcrette, J.-J.: Combining ERBE and ISCCP data to assess clouds in the Hadley Centre, ECMWF and LMD atmospheric climate models, Clim. Dynam., 17, 905-922, 2001.
Williams, J. H. T., Smith, R. S., Valdes, P. J., Booth, B. B. B., and Osprey, A.: Optimising the FAMOUS climate model: inclusion of global carbon cycling, Geosci. Model Dev., 6, 141-160, doi:10.5194/gmd-6-141-2013, 2013. 